\title{
$\mathrm{Ni}_{3} \mathrm{Al}$ partikülleri ile pekiştirilmiş bronz matrisli kompozitlerin kuru sürtünme ve aşınma davranışları
}

\section{Dry sliding friction and wear behaviours of bronze matrix composites reinforced with $\mathrm{Ni}_{3} \mathrm{Al}$ particles}

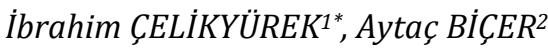

\begin{abstract}
${ }^{1}$ Metalurji ve Malzeme Mühendisliği Bölümü, Mühendislik-Mimarlık Fakültesi, Eskişehir Osmangazi Üniversitesi, Eskişehir, Türkiye. cibrahim@ogu.edu.tr

2Demirdöküm Bozüyük Tesisleri, Bilecik, Türkiye.

aytac.bicer@vaillant-group.com
\end{abstract}

Geliș Tarihi/Received: 03.02.2016, Kabul Tarihi/Accepted: 15.08.2016

* Yazışlan yazar/Corresponding author

doi: $10.5505 /$ pajes.2016.27136 Araștırma Makalesi/Research Article

Öz

$\mathrm{Ni}_{3} \mathrm{Al}$ partikülleri ile pekistirilmis bronz esaslı kompozit klasik toz metalurjisi (TM) tekniği ile üretilmiștir. Pekiștirici olarak kullanılan partiküller döküm $\mathrm{Ni}_{3} \mathrm{Al}$ alașımının bilyeli değirmende öğütülmesiyle üretilmiștir. Bronz alaşımı bileșenlerinin tozları ve $\mathrm{Ni}_{3} \mathrm{Al}$

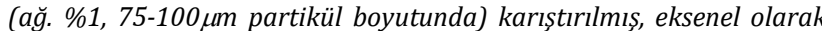
sıkıștırılmış ve sinterlenerek kompozit malzeme elde edilmiștir. Kompozit ışı mikroskobu ve taramalı elektron mikroskobu kullanılarak karakterize edilmistir. Basma mukavemetleri ve sertlikler belirlenmiştir. Kompozitin ve pekiştirilmemiş bronzun tribolojik özellikleri disk üzerinde pim geometrisinde belirlenmiș ve sonuçlar geleneksel fenolik reçine ile bağlanan fren balatası ile karşılaștırılmıștır. Sonuçlar TM bronzun kompozitten daha mukavemetli olduğunu göstermiștir. Kompozitin sertliği TM bronzdan daha yüksektir. Sürtünme ve aşınma testleri kompozitin așınma direncinin ve sürtünme katsayısının geleneksel balatadan daha yüksek olduğunu açığa çıkarmıştır.

Anahtar kelimeler: Metal matrisli kompozitler, Fren balatası, Mukavemet, Sertlik, Sürtünme ve așınma

\section{Giris}

Frenler tașitlardaki en önemli güvenlik ve performans bileșenlerinden birisidir[1]. Otomotiv fren sistemi metalik bir fren diski veya kampana ve fren balatası veya pabucundan oluşur[2]. Frenler, hareket halindeki aracın yavaşlatılması veya durdurulması sırasında kinetik enerjiyi sürtünme ile ısı enerjisine dönüștüren sistemlerdir[3]. Günümüzde kullanılan frenlerde disk veya kampana değișik dökme demirlerden yapılırken balata veya pabuçlar polimer matrisli kompozit şeklinde üretilmektedir.

Fren balata malzemelerinde sürtünme katsayısı oldukça yüksek olmalı, daha önemlisi değișen sürtünme şartlarında değișmemelidir. Sürtünme katsayısı zamanla, sıcaklıktaki değişimle, nemle, aşınma ve korozyon etkileriyle, yoldan sıçrayabilecek toz ve su ile vb. değișmemelidir. Bunlara ilaveten güvenlik için uzun ömürlü olmalı ve konfor için titreşim ve sese neden olmamalıdır[4]. Bundan başka aşınma direncinin yüksek olması, karșı malzemeyi çizip hasara uğratmaması, mekanik mukavemetinin yeterli olması da gerekir[5]. Ayrıca sertlik, basma mukavemeti ve yüksek sıcaklıklara direnç gibi mekanik özelliklerin iyi bir kombinasyonunu sağlamalıdır[3].

Asbest dolgulu fren balatalarının yasaklanmasından sonra günümüzde genellikle fenolik reçineler ile bağlanmış
Abstract

The bronze based composite reinforced with $\mathrm{Ni}_{3} \mathrm{Al}$ particles was produced by classical powder metallurgy (PM) technique. Particles used as reinforcement were produced via ball milling of $\mathrm{Ni}_{3} \mathrm{Al}$ cast alloy. The powders of constituents of bronze and $\mathrm{Ni}_{3} \mathrm{Al}$ powder (1\%wt.75-100 um particle in size) were mixed, compacted axially and sintered. The composite was characterized using light microscopy and scanning electron microscopy. The compression strength and hardness of composites were determined. The tribological properties of composite and unreinforced bronze were determined at pin-on-disc geometry and results were compared with conventional phenolic resin bonded brake lining. The results revealed that PM bronze has higher strength than composite. The hardness of composite is higher than PM bronze. The sliding and wear tests revealed that the wear resistance and coefficient of friction of composite are higher than conventional brake lining.

Keywords:Metal matrix composites, Brake lining, Strength, Hardness, Friction and wear

içeriğinde 10'dan fazla bazen 20-25 değișik katkı bulunan kompozit balatalar kullanılmaktadır.[1],[4]. Bu bileşenlerin ișlevleri 4 ana grupta toplanabilir; bağlayıcı, yapısal malzemeler, dolgular ve sürtünmeyi ayarlayıcılar. Bağlayıcı katkı malzemelerini bir arada tutar, yapısal malzemeler kompozit matrisine destek sağlar, dolgular balataya hacim kazandırırlar ve maliyeti düşürürler, sürtünmeyi modifiye eden katkılar da sürtünme katsayısını kararlı tutarlar[1],[6].

Otomotiv frenlerinin sürtünme davranışları disk, balata ve bu iki yüzey arasındaki üçüncü cisimlerin aktif yüzeylerinin karakteri ile belirlenir. Bu tribo sistem çok karmaşık ve değișkendir ve hala tam olarak anlașllabilmiș değildir[7]. Ara yüzey davranışlarının net bir şekilde belirlenememesinin en önemli nedenlerinden birisi farklı karakterde çok sayıda katkı malzemesi içermesidir. Fenolik reçine esaslı fren balatalarının geliștirilmesine yönelik araştırma çalışmaları sürtünmeyi artırma, aşınmayı azaltma, konforu artırma, kullanım sıcaklığını artırma ve maliyeti düșürme vs. özelliklerin üzerine odaklanmaktadır.

Bir fren malzemesinden beklentilerin çok fazla olması araștırmacıları farklı malzemelere de yöneltmiștir. Metal matrisli kompozitler iyi bir balata malzemesi olarak önerilmektedir[8]-[12]. Metalik katkılar fenolik esaslı fren balatalarının tribolojik özelliklerini geliștirmek için zaten kullanılıyordu[13],[14]. Metal esaslı balataların polimer esashı balatalara göre enerjiyi daha hızlı absorblama, daha yüksek 
aşınma direnci, daha yüksek sıcaklıklarda çalışabilme ve ısıyı daha hızlı iletme gibi üstünlükleri vardır[5]. Metal matrisli sürtünme kompozitlerinde matris malzemesi olarak Aluminyum, Bakır ve bunların alaşımları önerilirken sürtünmeyi ve aşınmayı kontrol etmek için de genellikle $\mathrm{Al}_{2} \mathrm{O}_{3}$ ve $\mathrm{SiC}$ gibi seramik esaslı malzemeler kullanılmaktadır[8],[10].

Metaller arası bileşikler özellikle yüksek sıcaklıklardaki yüksek mekanik özellikleri ve oksidasyon dirençleriyle metalik malzemelerin yeni bir sınıfını oluşturmaktadır. Bunlar içinde aluminatlar özel bir sınıfı oluşturur. Nikel aluminatlar yüksek sıcaklıklardaki üstün özellikleri yanında hem düşük hem de yüksek sıcaklık uygulamalarındaki üstün sürtünme ve aşınma davranışlarıyla da dikkat çekmektedir. $\mathrm{Ni}_{3} \mathrm{Al}$ alaşımının hem matris olarak hem pekiştirici olarak hem de kaplama olarak kullanımının önerildiği birçok çalışma mevcuttur[15]-[17].

$\mathrm{Bu}$ çalışmada, $\mathrm{Ni}_{3} \mathrm{Al}$ partikülleri ile pekiştirilmiş bronz matrisli kompozitler klasik toz metalurjisi tekniğiyle üretilmiş, kompozitlerin sürtünme ve aşınma davranışları belirlenmiş ve bulgular konvansiyonel fenolik esaslı fren balatası ile karşılaştırılarak değerlendirme yapılmıştır.

\section{Deneysel çalışmalar}

Kompozitlerin üretiminde pekiștirici olarak kullanılan $\mathrm{Ni}_{3} \mathrm{Al}$ alaşımı \%99.9 saflıktaki Ni ve \%99.7 saflıktaki Al'nin vakumlu ark ergitme ocağında stokiometrik bileşimde ergitilmesiyle üretilmiştir. Oksitlenmeyi önlemek için ocak önce $5 \times 10^{-2} \mathrm{mbar}$ seviyesine vakumlanmıș, daha sonra saf $\mathrm{Ar}$ gazı ile doldurulmuştur. Dökümü yapılan alaşım gezegensel hareketli bilyeli değirmende ögütülmüș ve elenerek $75 \mu \mathrm{m}$ 'den büyük $100 \mu$ m'den küçük partiküller ayrılmıștır. $\mathrm{Bu}$ partiküller kompozitte pekiştirici olarak kullanılmıştır. Matris ise nominal bileșimi Tablo 1'de verilen yatak alaşımıdır. Yatak alaşımının hazırlanmasında bileşimi oluşturan elementlerin tozları kullanılmıștır.

Tablo 1:Matris malzemesinin nominal bileşimi (\%ağ.)

\begin{tabular}{lllll}
\hline Bakır & Kalay & Demir & Kurşun & Grafit \\
\hline 70 & 8 & 11 & 8.5 & 2.5 \\
\hline
\end{tabular}

Yatak alaşımı bileșimine sahip matrise ağırlıkça \%1 oranında $\mathrm{Ni}_{3} \mathrm{Al}$ partikülleri ilave edilerek karıştırılmış ve karışım eksenel olarak $300 \mathrm{MPa}$ basınç ile preslenmiştir. Preslenen numuneler kuartz tüplere konulup vakumlanmış ve $820^{\circ} \mathrm{C}$ sıcaklığa $40 \mathrm{dk}$. çıkılarak bu sıcaklıkta $20 \mathrm{dk}$. süreyle sinterlenmiștir. Sinterlenen numuneler firında kendi halinde soğutulmuştur. Böylece $6 \mathrm{~mm}$ çapında ve $10 \mathrm{~mm}$ yüksekliğinde numuneler elde edilmiştir.

Sinterlenen numunelerin basma mukavemetleri ve sertlikleri ölçülmüş, mikro yapısı da ışı mikroskobu ve taramalı elektron mikroskobu kullanılarak incelenmiștir. Numunelere şematik olarak Şekil 1'de gösterilen CSM tribometre cihazında disk üzerinde pim geometrisinde kuru sürtünme ve aşınma testleri uygulanmıştır. İki farklı yük ve kayma hızı kullanılarak sürtünme ve aşınma davranışları belirlenmiş ve sonuçlar nominal bileşimi Tablo 2'de verilen konvansiyonel balata ile karşılaştırılmıştır. Sürtünme ve aşınma testlerinde karşı cisim olarak GG25 gri dökme demir kullanılmıştır. Her deney öncesinde dökme demir diskin yüzeyi parlatılarak yüzey pürüzlülüğü Ra=1.5 $\mu \mathrm{m}$ seviyesine getirilmiştir. Her test $2.000 \mathrm{~m}$ kayma mesafesinde gerçekleştirilmiş, numunedeki ağırlık kaybı ölçülmüş ve toplamda 10.000 m'ye kadar testlere devam edilmiştir. Aşınma miktarları ağırlık kayıplarının malzeme yoğunluğuna bölünmesiyle bulunan aşınma hacimleri şeklinde tespit edilmiştir.

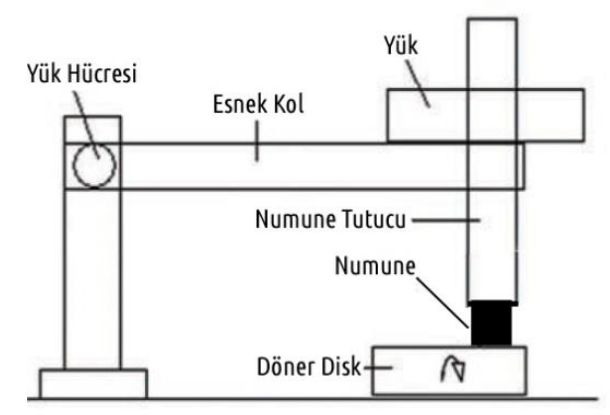

Şekil 1: Tribometre cihazının şematik görünümü.

Tablo 2. Konvansiyonel fren balatasının nominal bileșimi.

\begin{tabular}{lc}
\hline Fenolik reçine & 29 \\
Demir & 11 \\
Karbon & 15 \\
Kireç taşı & 12.6 \\
Aluminyumoksit & 0.8 \\
Sentetik demiroksit & 9.9 \\
Vermikülit & 14.9 \\
Çinko & 2.5 \\
Diğer & 4.3 \\
\hline
\end{tabular}

\section{Bulgular ve tartışma}

Matris alaşımı, kompozit ve GG25 malzemesine ait basma mukavemeti ve sertlik değerleri Tablo 3'te özetlenmiştir. Tablodan görüldügü gibi partikül ilavesi yatak alaşımı matrisin mukavemetini düşürürken sertliğinde artışa neden olmuştur. Partiküllerle pekiştirilmiş kompozitlerde pekiştirici ilavesinin matrisin mukavemetini düșürücü veya artırıcı etkisinin olabileceği daha önceki çalışmalarda ifade edilmiştir[18]. Sertlikteki artışın nedeni pekiştirici sertliğinin matristen daha yüksek olmasıdır.

Tablo 3: Deney numunelerin mekanik özellikleri.

\begin{tabular}{cccc}
\hline & Matris & Kompozit & GG25 \\
\hline $\begin{array}{c}\text { \%0.2 Basma akma } \\
\text { mukavemeti (MPa) }\end{array}$ & 344 & 54 & - \\
Sertlik (HV) & 42 & 80 & 275 \\
\hline
\end{tabular}

Şekil 2'de üretilen matris ve kompozitin optik mikro yapıları görülmektedir. Şekil $2 b$ 'de görüldüğ̈̈ gibi $\mathrm{Ni}_{3} \mathrm{Al}$ partikülleri matris içinde homojen bir biçimde dağılmış ve matris ile bağlanmıștır. Uygulanan sinterleme sürecinde metalik karakterdeki partiküllerin matris içinde çözünmeden kaldı̆̆ da görülmektedir.

Sürtünme ve aşınma testleri 10 ve $15 \mathrm{~N}$ normal yük, 1 ve $1.5 \mathrm{~m} / \mathrm{s}$ kayma hızlarında gerçekleștirilmiştir. Kayma mesafesiyle kümülatif aşınma miktarları Şekil 3'te verilmiştir. Şekillerden konvansiyonel balatanın ve kompozitin kayma mesafesine bağlı olarak benzer aşınma davranışı sergilediği görülmektedir. Tüm sürtünme koşullarında konvansiyonel balata kompozitten daha düşük aşınma direncine sahiptir. Matris malzemesi olan yatak alaşımı ise her ikisinden de yüksek aşınma direnci göstermektedir. 
Şekil 4'te $10.000 \mathrm{~m}$ kayma mesafesinde numunelerdeki spesifik așınma hızları verilmiștir. Șekilden yükün ve kayma hızının değişmesiyle aşınma hızının hem kompozitte hem de konvansiyonel balatada değiștiği görülmektedir. Konvansiyonel balatada düşük yüklerde kayma hızı arttıkça aşınma direnci artarken daha yüksek yüklerde kayma hızının artması aşınma direncinin azalmasıyla sonuçlanmıştır.Kompozit malzemede ise düşük yüklerde kayma hızının artmasıyla aşınma direnci azalırken yüksek yüklerde kayma hızının artmasıyla aşınma direnci bir miktar artmaktadır.

Sürtünme koşullarının kompozit ve konvansiyonel balata malzemesinin sürtünme katsayısına etkileri Şekil 5'te gösterilmektedir. Genel olarak tüm sürtünme koşullarında kompozit malzeme konvansiyonel balatadan daha yüksek sürtünme katsayısına sahiptir. Kompozit malzemede sürtünme katsayısının yüksek olması içerdiği $\mathrm{Ni}_{3} \mathrm{Al}$

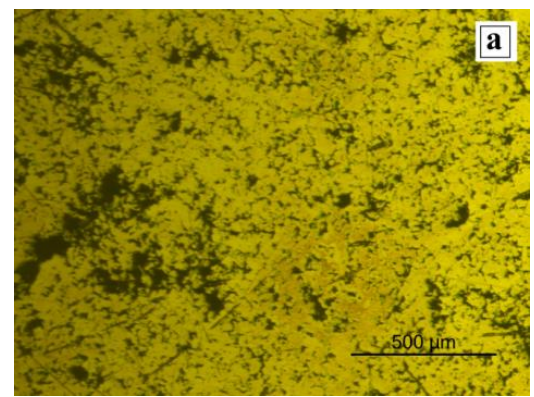

partiküllerinden kaynaklanmaktadır. Çünkü matris malzemesinin sürtünme katsayısı daha düşüktür.

Matrisin, kompozitin ve konvansiyonel balatanın aşınma testinden sonraki aşınmış yüzey SEM mikro yapılarının bazıları ise Şekil 6'da verilmiştir. Karşı cisim olan dökme demirin sertliği hem kompozitten hem de balatadan çok daha yüksektir. Mikro yapılardan konvansiyonel balatada düşük yük ve kayma hızlarında çok az abrasif aşınmayla birlikte kısmi delaminasyon varken yüksek kayma basıncı ve hızında hakim aşınmanın adhesif aşınma olduğu görülmektedir (Şekil $6 a, b)$. Kompozit malzemede ise düșük kayma yükü ve hızında abrasif aşınma ve oluklanma ile plastik deformasyon görülürken (Şekil 6c) yüksek yük ve kayma hızlarında abrasif aşınmanın ve oluklanmanın azaldığı (Şekil 6d) görülmektedir. Hakim aşınma mekanizmasındaki değişimin nedeni artan yük ve hızın neden olduğu sürtünme ara yüzeyi sıcaklığındaki artıştır.

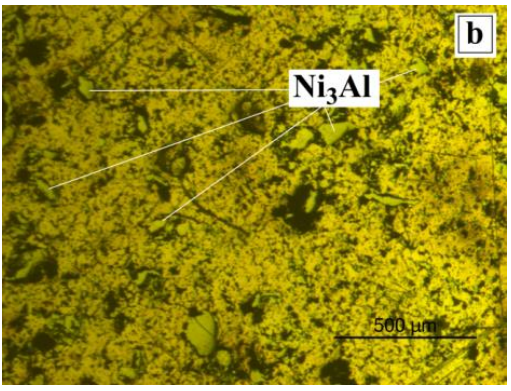

Şekil 2:(a): Matris ve,(b): Kompozitin optik mikro yapısı.
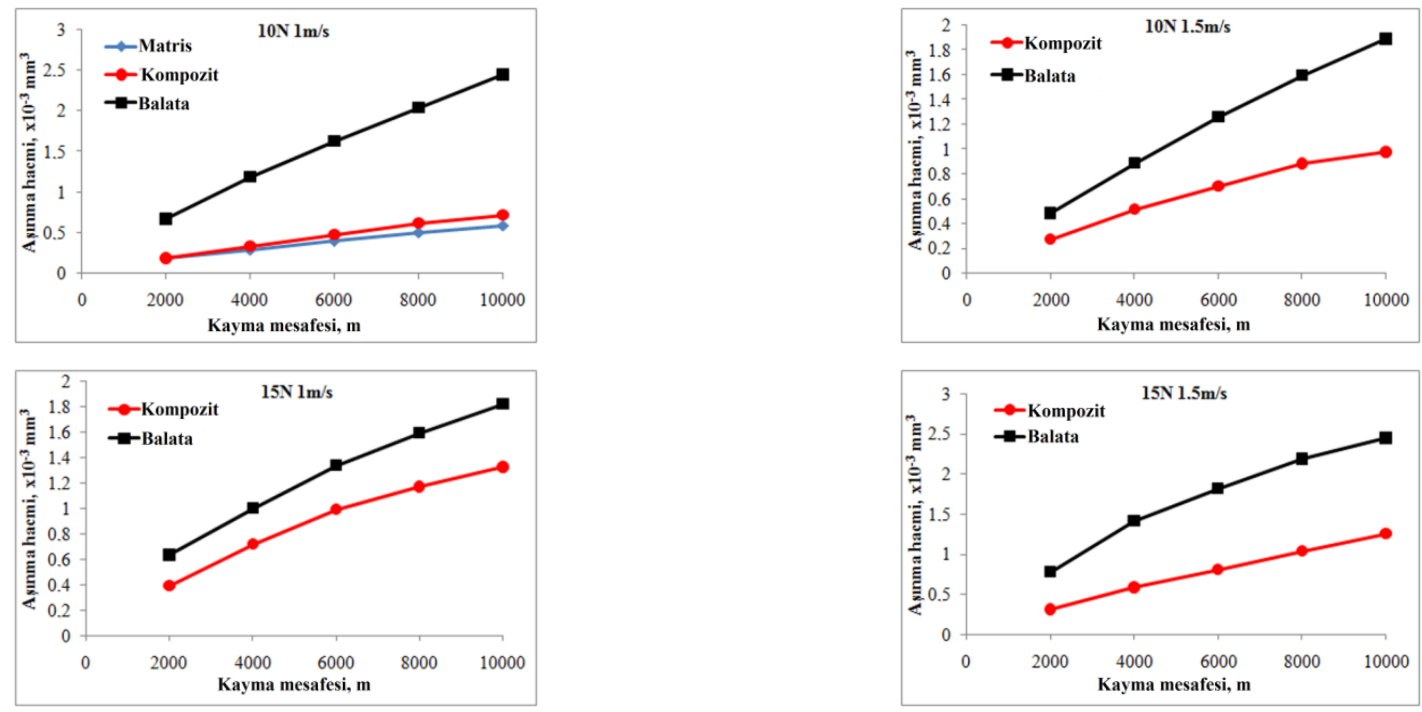

Şekil 3: Farklı sürtünme koşullarında aşınma miktarının kayma mesafesiyle değişimi.

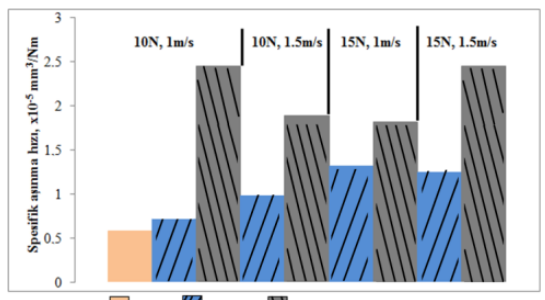

$\square$ Matris $\mathbb{Z}_{\text {Kompooit }} \square \rrbracket_{\text {Balata }}$

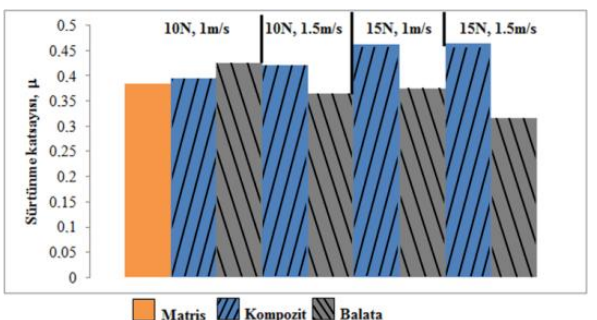

Şekil 5: Farklı sürtünme koșullarındaki sürtünme katsayıları.

Şekil 4: Farklı sürtünme koşullarındaki spesifik aşınma hızları. 


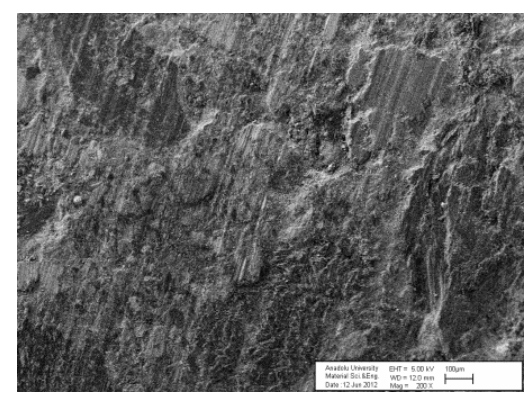

(a)

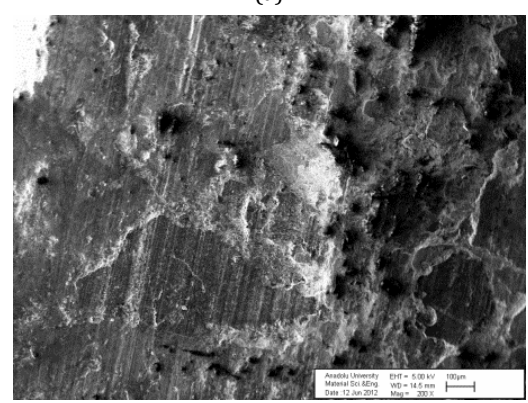

(b)

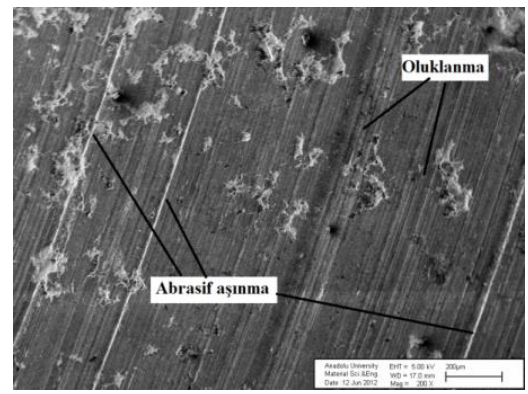

(c)

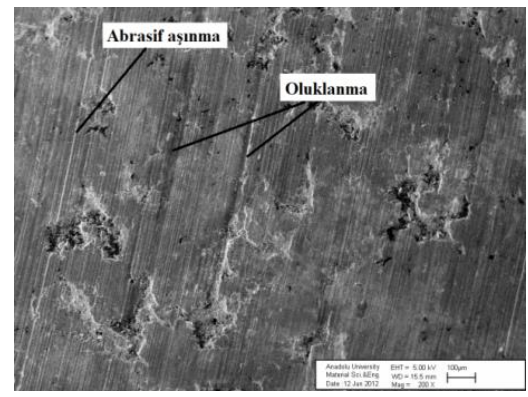

(d)

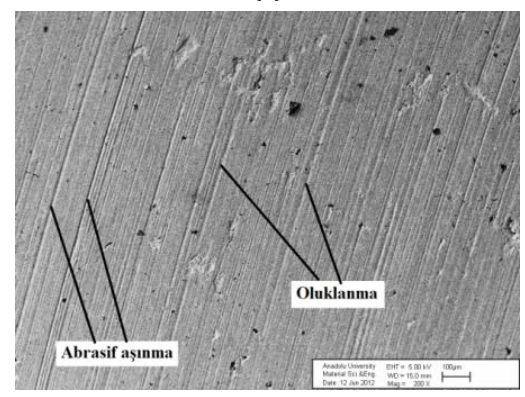

(e)

Şekil 6: Așınmış yüzeylerin mikro yapıları. (a):Balata $10 \mathrm{~N}$ yük $1 \mathrm{~m} / \mathrm{s}$, (b):Balata $15 \mathrm{~N}$ yük $1.5 \mathrm{~m} / \mathrm{s}$, (c):Kompozit $10 \mathrm{~N}$ yük $1 \mathrm{~m} / \mathrm{s}$,

(d): kompozit $15 \mathrm{~N}$ yük $1.5 \mathrm{~m} / \mathrm{s}$, (e):Matris $10 \mathrm{~N}$ yük $1 \mathrm{~m} / \mathrm{s}$ hiz.
Temas halinde birbiri ile sürtünme hareketi yapan malzemelerde hakim aşınma mekanizmasının temas halindeki malzemelerin mekanik özelliklerine ve sürtünme koşullarına (kayma basıncl, kayma hızl, ortam vs.) bağlı olduğu bilinmektedir. Polimer matrisli kompozitten daha yüksek mekanik özelliklere sahip olan bronz matrisli kompozitte plastik deformasyonun daha zor olması sürtünme katsayısının da daha yüksek olmasıyla sonuçlanmıştır. Sürtünme kuvvetlerinin oluşmasındaki önemli unsurlardan bir tanesi de ara yüzeyde oluşan adhesif bağlanmadır. Metalik karakterdeki malzemeler arasında oluşabilecek adhesif bağlanmanın metalpolimer arasındaki bağlanmadan daha yüksek olacağı da açıktır. Sürtünme testlerinde elde edilen sürtünme katsayıları, sonrasında ölçülen aşınma hacimleri ve aşınmış yüzey mikro yapıları birlikte değerlendirildiğinde kompozitlerin kuru sürtünme ve aşınmasında plastik deformasyon (oluklanma ve delaminasyon) ve abrasif aşınmanın rol aldığı görülmektedir.

\section{Sonuçlar}

$\mathrm{Ni}_{3} \mathrm{Al}$ partikülleri ile pekiştirilmiş yatak alaşımı bileşimine sahip metal matrisli kompozit klasik toz metalurjisi tekniği ile üretilebilir. Uygun sinterleme şartlarında $\mathrm{Ni}_{3} \mathrm{Al}$ partikülleri matris içinde çözünmeden kalabilir. Metalik karakterdeki $\mathrm{Ni}_{3} \mathrm{Al}$ metaller arası bileșiği seramik karakterdeki pekiştiricilere göre metal matris ile daha iyi bir ara yüzey bağı olușturabilir. Böylece așınma direncine daha iyi katkı sağlayabilir. Ara yüzey bağının iyi olmaması durumunda matristen ayrılan pekiştirici partiküller aşınma direncini artırma yerine azaltıcı etki gösterebilir. Seramikler gibi çok yüksek sertliğe sahip olmayan $\mathrm{Ni}_{3} \mathrm{Al}$ kompozitin aşınma direncini artırırken sürtündüğü karşı yüzeyi çok fazla hasara uğratmaz. Yatak alaşımına ilave edilen $\% 1 \mathrm{Ni}_{3} \mathrm{Al}$ sürtünme katsayısını artırırken alaşıma konvansiyonel balata malzemesinden daha yüksek aşınma direnci kazandırır. Konvansiyonel balata ile karşılaştırıldığında, sağladığı diğer avantajların yanında, yapı bileșen sayısı daha az olan kompozit malzemede sürtünme ve aşınma davranışlarını kontrol etmek çok daha kolay olabilir.

\section{Kaynaklar}

[1] Mohanty S, Chugh YP. "Devolopment of fly ash-based automotive brake lining". Tribology International, 40(7), 1217-1224, 2007.

[2] Kukutschova J, Roubicek V, Maslan M, Jancik D, Slovak V, Malachova K, Pavlickova Z, Filip P. "Wear performance and wear debris of semimetallic automative brake materials". Wear, 268(1-2), 86-93, 2010.

[3] Sellami A, Kchaou M, Elleuch R, Cristol AL, Desplanques Y. "Study of the interaction between microstructure, mechanical and tribo-performance of a commercial brake lining material". Material and Design, 59, 84-93, 2014.

[4] Mutlu I, Eldogan O, Findik F. "Tribological properties of some phenolic composites suggested for automotive brakes". Tribology International, 39(4), 317-325, 2006.

[5] Boz M. Kurt A. "Toz metal fren balata malzemelerinin sürtünme-aşınma performansı üzerine Çinkonun etkisi". Gazi Universitesi Muhendislik-Mimarlık Fakültesi Dergisi, 21(1), 115-121, 2006.

[6] Kumar M, Bijwe J. "Composite friction metarials based on metallic fillers: Sensivity of $\mathrm{m}$ to operating variables". Tribology International, 44(2), 106-113, 2011. 
[7] Eriksson M, Jacobson S. "Tribological surfaces of organic brake pads". Tribology International, 33(12), 817-827, 2000.

[8] Boz M, Kurt A. "The effect of $\mathrm{Al} 2 \mathrm{O} 3$ on the friction performance of automative brake friction materials". Tribology International, 40(7), 1161-1169, 2007.

[9] Kurt A. Boz M. "Wear behavior of organic asbestos based and bronze based powder metal brake linings". Materials and Design, 26(8), 717-721, 2005.

[10] Hassan AM, Alrashdan A, Hayajneh MT, Mayyas AT. "Wear behavior of Al-Mg-Cu-based composites containing SiC particles". Tribology International, 42(8), 1230-1238, 2009.

[11] Gultekin D, Uysal M, Aslan S, Alaf M. Guler MO, Akbulut H. "The effects of applied load on the coefficient of friction in $\mathrm{Cu}-\mathrm{MMC}$ brake pad/Al-SiCp MMC brake disc system" Wear, 270(1-2), 73-82, 2010.

[12] Jia JH, Chen J, Zhou H, Wang J, Zhou H. "Friction and wear properties of bronze-graphite composite under water lubrication". Tribology International, 37(5), 423-429, 2004.
[13] Jang H, Ko K, Kim SJ, Basch RH, Fash JW. "The effect of metal fibers on the friction performance of automative brake friction materials". Wear, 256(3-4), 406-414, 2004.

[14] Ho SC, Lin JHC, Ju CP. "Effect of fiber addition on mechanical and tribological properties of a copper/phenolic-based friction material". Wear, 258(56), 861-869, 2005.

[15] Johnson ML, Mikkola DE. "Cavitation erosion and abrasive wear of $\mathrm{Ni}_{3} \mathrm{Al}$ alloys".Intermetallics, 3(5), 389396, 1995.

[16] Zhu S, Bi Q, Yang J, Liu W, Xue Q. "Effect of particle size on tribological behavior of Ni3Al matrix high temperature self-lubricating composites". Tribology International, 44(12), 1800-1809, 2011.

[17] Yu Y, Zhou J, Chen J, Zhou H, Guo C, Guo B. "Preparation, microstructure and tribological properties of $\mathrm{Ni}_{3} \mathrm{Al}$ intermetallic compound coating by laser cladding". Intermetallics, 18(5), 871-876, 2010.

[18] Celikyurek I, Korpe NO, Olcer T. Gurler R. "Microstructure, properties and wear behaviors of (Ni3Al)p reinforced $\mathrm{Cu}$ matrix composites". Journal of Materials Science and Technology, 27(10), 937-943, 2011. 